\title{
Japan's Diplomacy Strategy in Dealing with the Demographic Crisis through Modern Culture Anime
}

\author{
Silvya N. Priesca ${ }^{1}$, Mohammed Mossadeq Bahri ${ }^{2}$ \\ \{silvypriesca@gmail.com ${ }^{1}$, mossadeqbahri@gmail.com ${ }^{2}$ \} \\ Universitas Indonesia, Indonesia ${ }^{1,2}$
}

\begin{abstract}
Cooperation among countries is a necessity for every country to maintain their prosperity \& stability. One of the cooperation types is diplomacy, and the diplomacy type that is often used is cultural diplomacy One example that is actively carrying out international cooperation in this way is Japan. Japan's Government made the Japan Foundation as a cultural diplomacy agent to introduces their all culture to other countries. As its duties, the Japan Foundation has created programs that are to attracting people in the world (especially Asian people) to respect Japan. One example of JF is the Japanese Film Festival. As a result, several Indonesian people who work in Japan rapidly increased. Based on data from the ministry of health, labor, and welfare Japan, Indonesia in the top 8 countries for most foreign worker suppliers to Japan.
\end{abstract}

Keywords: The Japan Foundation, Japan, Cultural Diplomacy, Indonesia

\section{Introduction}

Each country must have needs and problems that cannot be solved by itself. Those need and interest commonly in the form of goods or even they need the protection of other countries. As the way out, cooperation among countries is needed in various ways, one of them is diplomacy. Diplomacy is an important thing to do nowadays, as stated by Melissen [1] with this following statement:

"Both small and large countries, ranging in size from the United States to Belgium or even Liechtenstein, and with either democratic or authoritarian regimes, such as China and Singapore, and including the most affluent, such as Norway, and those that can be counted among the world's poorest nations, for example, Ethiopia, has in recent years displayed a great interest in public diplomacy".

Based on Melissen's statement, no matter how wide the country area, the adopted model of government, and the poverty in the country, they have to implement diplomacy. Furthermore, diplomacy (public diplomacy) has been done by each country, and the diplomacy type that is often used is cultural diplomacy.

The cultural diplomacy is not a new thing in politics, such as the United States which has been implementing it since a long time ago. This is as stated by Feigenbaum [2]:

“... the US government has a long-term commitment to promoting mutual understanding by fostering international cultural relations. US government 
programs to this end have taken the form of exchanges, on the one hand, and public diplomacy, on the other".

The US government gives a role model of cultural diplomacy which obtained 2 advantages, such as cultural exchange with other countries and also public diplomacy can be done. Feigenbaum [2] also states that the advantage of cultural exchange would allow people from other countries to more understand their culture. After the US did cultural diplomacy, afterward many countries obtained cultural diplomacy to meet their country's interests.

Besides America, another country that also did cultural diplomacy especially in the region of Asia is Japan. The seriousness of Japan in implementing its cultural diplomacy was manifested by the establishment of government official institutions, the Japan Foundation which acts as an agent for their cultural diplomacy. The Japan Foundation is a cultural institution that is sponsored and mandated by the Japanese nation-state to facilitate international understanding and friendship between Japan and other nations through a cultural exchange "to contribute to the advancement of cultures of the world and the welfare of humanity" [3].

First established in 1972 as a special legal entity under the jurisdiction of the Ministry of Foreign Affairs, the JF now consists of three cultural institutes, seven cultural centers, nine liaison offices, and seven affiliated Japanese language centers in 19 overseas locations, as well as two Japanese language institutes in Japan.

As its duty, the Japan Foundation has various programs to promote their traditional and modern culture of Japan as the soft power of Japan to interest other countries to have an agreement with Japan. The Japanese traditional culture to promote is ikebana, chanoyu. Meanwhile, for popular culture, the government and the Japan Foundation put effort to promote anime around the world. For anime, the Japan Foundation holds an annual event to show Japanese drama and anime, the Japanese Film Festival.

But why Japan chooses anime as their tools for cultural diplomacy? Based on an online survey by Philanthropic Organization Nippon Foundation conducted on 1,000 Japanese teenagers between the ages of 17-19. When they asked about "what is the best thing from Japan?" most respondents answer "Anime \& manga".

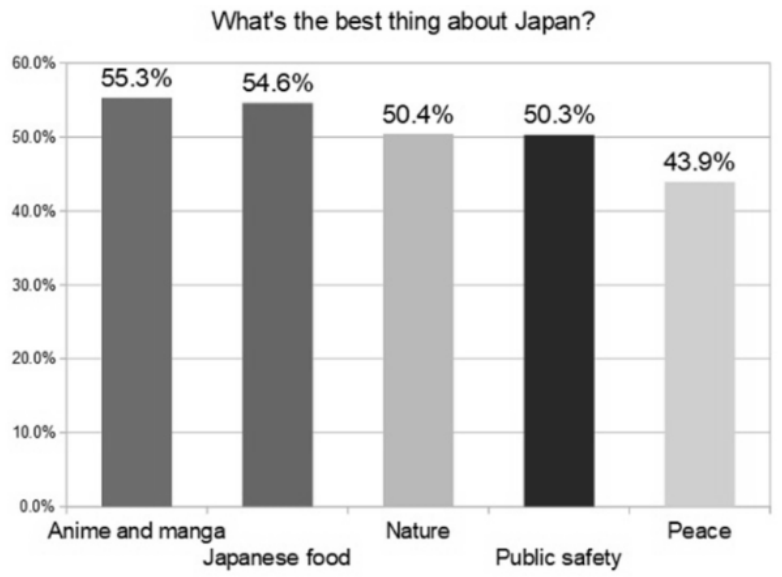

Fig. 1. "What is the best thing from Japan" Survey by the Nippon Foundation result. 
The use of anime as Japan's soft power to impress other countries even officially stated by Japan government on their official website (MOFA):

"The Ministry of Foreign Affairs, aiming to further the understanding and trust of Japan, is using pop-culture, in addition to traditional culture and art, as its primary tools for cultural diplomacy. Among young people, pop-culture, such as Manga and Anime, has been popular worldwide in recent years".

Based on the statement above, it can be concluded that anime and manga have considerable potential as cultural diplomacy instruments due to their popularity and have great demand by many people around the world. Therefore, it is not surprising that the Japanese government is promoting Japanese pop-culture, especially anime to make it easier to attract the world community towards Japan.

And then the Japanese government use their pop culture to solve their problem in Japan. As we know, Japan has started a demographic crisis. So, the Japanese government using their pop culture; anime as their soft power to attract so many people in the world to work in Japan, especially for blue-collar workers.

\section{Methodology}

The methodology used in this study are literature review and quantitative data by using secondary data in the form of a survey that published by the Ministry of Health, Labor and Welfare of Japan, Philanthropic Organization Nippon Foundation, Japanese tourism organization, Japanese travel agent (Indonesia branch), and Japanese official website (MOFA) to be analyzed. To grasp how Japanese pop culture attracts many people around the world to learn the Japanese language or even to work in Japan. This study explaining what is the reason Japan implementing cultural diplomacy to other countries (especially Asian countries), and what is the impact of Japanese cultural diplomacy for Japan and other countries. This study also explains one of the Japan's social problem as the reasons for those Japan's cultural diplomacy, which is the demographic crisis and its causes.

\section{Findings and Discussion}

The cultural diplomacy that obtained by the country due to the needs and interests of the country. Each need and interest will be changing day by day. As experienced by Japan today, the problems and needs experienced changes, particularly after the economic maturity period. Based on a survey by the ministry of health, welfare, and labor, Japan has already started the demographic crisis, where the number of elder people is higher than children, with the details as follows figure 2 : 


\section{Births/Deaths and Marriages/Divorces by Year}

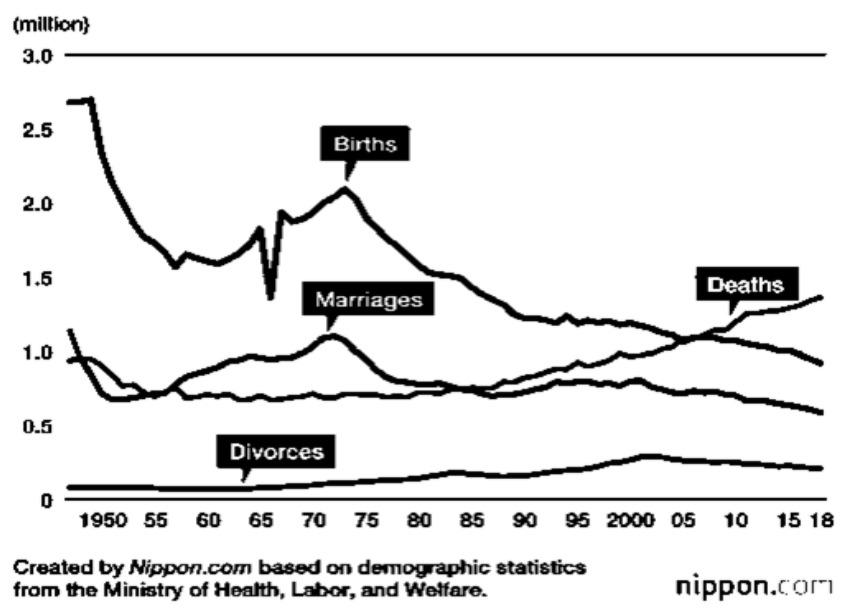

Fig. 2. Birth/Death and Marriages/Divorce by Year Data.

The initial factors of the Japanese demographic crisis as follows:

\subsection{Mindset Changing of Economic Maturity}

Japan's development to enter the economic maturity phase, as stated by Abegglen [4] "No state that changes its industrial structure, as fast as Japan". This is indicated by several facts including the improvement in the number of Japanese GDP 60 times within 40 years, in addition to the Japanese currency 'JPY' to 'Dollar' which improves as many as 200 times. Both of these are evidence of remarkable development in Japan's economic structure.

Japan's success in reaching economic maturity is after experiencing transition in terms of output, income, and technology. Moreover, in the early 1990s, which was a shifting phase for the Japanese economy and community where industry and demographics experienced high growth. Yet in 1998 Japan experienced social maturity where the number of people aged 65 years old was numerous rather than those aged 15 years and under. This shows that Japan has reached the peak of the average age of workers also a new problem due to the number of workers and the population is declining.

All of the efforts and challenges faced by Japan in growth are not as hard as the economy maturity phase. The high saving of the Japanese people makes it more difficult for the country and consumptive people is needed by the country. For example, Japan as an industrial country that produces a lot of goods but due to the extraordinary saving of society and the demographic crisis, the amount of consumption will not be balanced with production. During this period efforts were also made where the company's balance sheet had to be strengthened, the amount of debt must be reduced. There was a mindset changing in the perspective about a successful company is seen from its profitability, due to high capital will be happened if the company participates in the share market. In focusing on profitability, company growth will be easier. What must be pay attention is the sustainability of the resources that companies have. All of these systems and mindset changes show that it is not easy to deal with changing conditions, especially when Japan has already experienced an economic recession in 1998-1999. 


\subsection{Unmarried People}

After entering a period of maturity, many Japanese women also enter the working profession. More and more women are aware of the existence of gender discrimination, many of them decide to go study abroad. Most of them study abroad to improve their quality so they can compete with men in the working profession after returning to Japan. This phenomenon was stated by Kelsky [5] "Almost all women affected by discrimination in the working professionals that make them motivated to study abroad".

Besides discrimination, another reason is men dominated in the working professional, as one example is Japanese student 'Kitahara Satoko' statement in Kelsky [5] "The first thing that made me decide to study in America is male domination ... Then what occurred to me was to study English in America so that I could meet international qualifications". It was not enough for Japanese women to compete with men. After the women prepared themselves by receiving their higher education, upon entering the working professional, they face difficulties in the company system. Women are demanding given opportunities equal to men about high positions in the company, while the consequences of women demanded by companies in the ability to work and loyalty as men. Due to the demand for high loyalty, women must work for many hours.

Long working hours are not a problem for men, because it is the main task of men as breadwinners and working outside the home. Unlike the main task of women should also do domestic affairs, so working long hours becomes a dilemma for women. Moreover, sometimes overtime is needed to complete the work. Japan is known as the country with the longest working hours of its employees in the world. As reported by CNBC in the article "Japan has some of the longest working hours in the world. It's trying to change" based on a survey in 2016 that Japanese workers take overtime at least 80 hours per week. These factors make women must be faced with choices if they are married then they must manage their responsibility of taking care of household and family, but they cannot focus on a career to get a high position. Considering the preparations that have been made by women since getting an education to compete with men, and the hope of parents who want their children to be successful is a consideration for women if she only becomes a housewife who cannot even be independent financially.

\subsection{Japanese Public Sex Interest is Declining}

No free sex prohibition makes young people, especially women so comfortable with the situation of being single. Therefore, they can have a career without the obligation to take care of the household. There are even surprising facts in Japan about a large number of single men and women who have never had sex. Based on data which quoted from Japan times in an article titled In sexless japan, almost half of young men and women are virgins: a survey, the survey states that half the number of women and single men in Japan claim to be virgin or have never had sex. This shows that Japanese people do not even think about sex even though there is no prohibition on free sex. Based on the data, sex not so important for Japanese single men and women.

As reported by Nippon.com in the article entitled "Loveless and single and happy that way - Survey of light sheds on young people's relationships" based on a survey that conducted from 1987 to 2015, since 2005 there has been an improvement of the number of people who are single without sexual experience in this following data: 


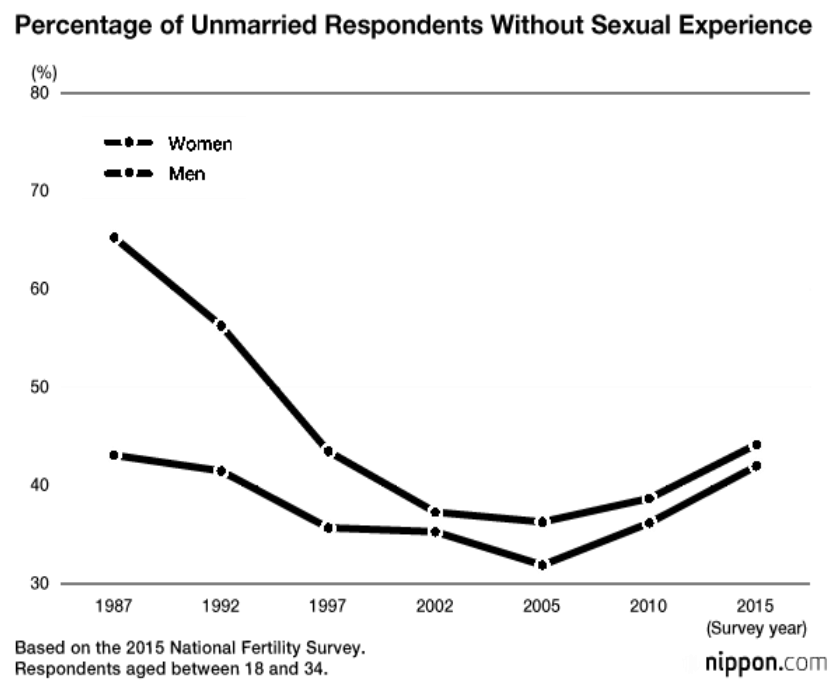

Fig. 3. Percentage of Unmarried Respondents without Sexual Experience.

\subsection{Finance Ability of Men}

The factors that have been disclosed previously become the factors that are considered by women, so it is so hard to decide to get married. There are also factors of men who also impact on women, most of the men are employees who have contract status, they doubt to get married because they do not have good financial stability. Many companies employ their employees as contract employees so that employees worry that one day the contract will be terminated unilaterally. Therefore, men who work as contract employees must try to be "secure" financially to decide on marriage. Moreover, the problem impacts to postpone the marriage.

Many factors consider youth, especially women, to delay and even decide not to marry. Particularly if they have managed to achieve the position they want in a company and financially independent, so they no longer need to have husbands, they view marriage as only a burden because their focus and time must be divided to take care of the household. The phenomenon of women in Japan who are not married or called josei no hikonka. This phenomenon is improving every year based on surveys since 1970 known to be $5 \%$ and rose to $16 \%$ in 2010 .

This Josei no hikonka phenomenon is mostly found in metropolitan cities, most commonly in Tokyo. The factors mentioned previously experienced by Japanese women who live in Tokyo, they try to be financially independent to meet their personal needs. The data on the percentage of Hikonka numbers, especially in the phenomenon of Josei no Hikonka, based on surveys obtained by the government between 1970 and 2010 has improved for both men and women.

The phenomenon of Hikonka or unmarried men and women begins when Japanese youth postpone the age of marriage, there are Japanese people who even though they are 50 years old but still not married. Japanese people who are at least 50 years old and not yet married are then considered to have decided not to marry. Therefore, surveys conducted in the calculation of the number of unmarried people are usually calculated based on age over 50 years. 
The phenomenon of hikonka has improved since 1970 and continues until 2010. The number of hikonka both men and women 5\% in 1970 and rose to $16 \%$ in 2010, as reported by economist.com in the following figure 4:

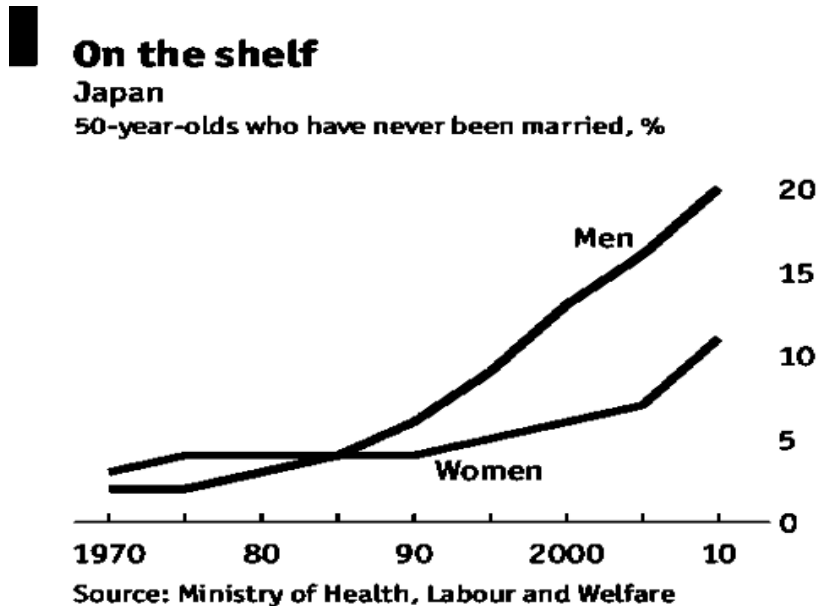

Econunist.com

Fig. 4. Percentage of 50 years old who have never been married.

The data shows the desire of Japanese men and women to get married is declining from time to time.

Those phenomena are the cause of Japan's demographic crisis. Japan's government realized that a demographic crisis is crucial because it impacts the lack of employment. Although Japan has tried to overcome these problems by using Artificial Intelligence to replace several human occupational positions, it is undeniable that human roles cannot be fully replaced by robots. Also, both the Japanese government and the private sector are trying other solutions to extending the retirement age. In the mid of 1950s, the average age of retirement was 55 years but when it was 65 years except for directors. This shows that employment depends on the status of his position. As we know, after retirement it is common for Japanese employees to return to work, they have to choose to fill different positions in the same company or the same position (even higher) in different companies. One example is the Matsushita company that provides employment opportunities for elder employees to continue with jobs that are not overly required physically, and the time is also flexible.

By the economics condition, making the Japanese have a high standard, becomes the main factor of Japanese workers. The immigrants mainly do not have particular skill will work in a place that not has the high interest of Japanese people that have these categories $3 \mathrm{~K}$ (Kitanai, Kitsui, Kiken). Based on a survey by the Japanese Ministry of Health, Labor and Social Affairs that released the data of foreign workers number as these following details: 


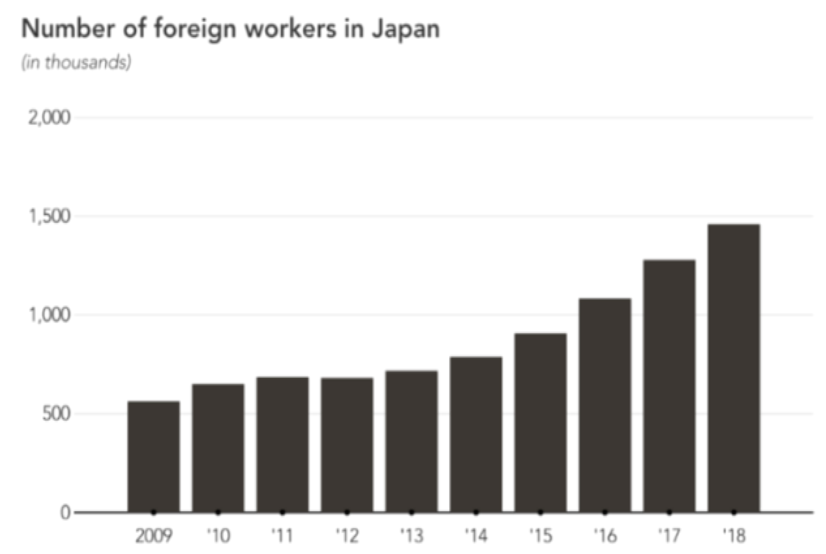

Source: The Ministry of Health, Labor and Welfare

Fig. 5. Number of foreign workers in Japan.

Based on these data, it is clearly illustrated that the number of foreign workers in Japan improves every year. Also, the Ministry of Health, Labor and Social Affairs of Japan issued the list of which countries sent the most foreign workers to Japan, including:

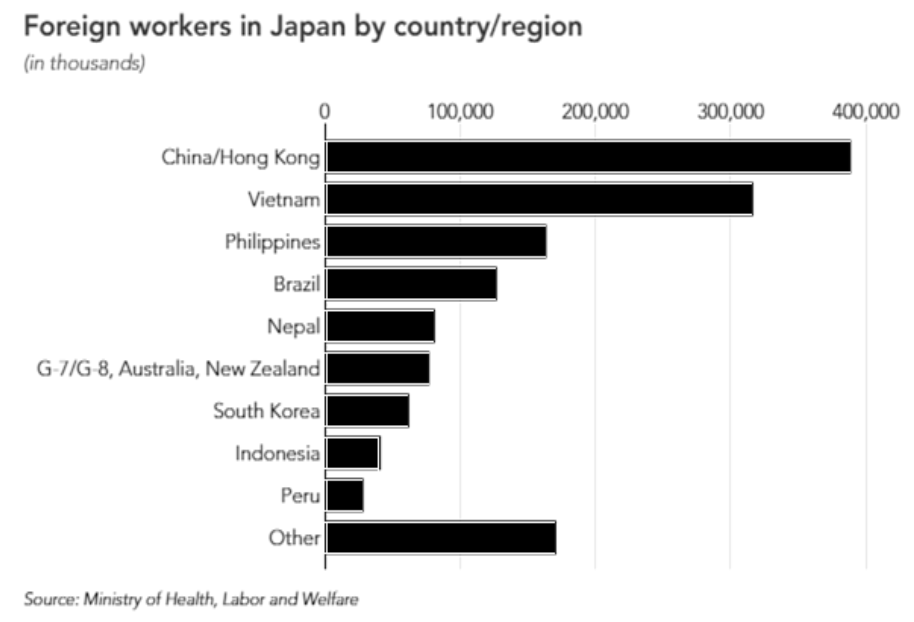

Fig. 6. Foreign workers in Japan by country/region.

Based on the data, it is known that countries supplying labor to Japan are mostly from Asian countries, although some are from European countries. Even Indonesia itself is included in the top 9 countries, that most supplied labor to Japan, it is showing an enthusiasm of Indonesian people to work in Japan.

The phenomenon of a large number of immigrant workers in Japan occurs in dual labor market theory, there are an internal factor and external factor between immigrants and the Japanese government. In this theory, Piore in Massey [6] revealed that it was stated that "international migration is caused by the demand for immigrant labor in the economic structure 
of developed countries". Based on that statement, international migration comes from the demands of labor from the modern industrial society as Japan. As a result, there are not only young people in need of a high salary, but Japan also actually needs them to support their industrial development.

Japan diplomacy strategy is not only succeeding to attract people around the world especially Asian people to work in Japan. There is another impact of the Japanese culture diplomacy towards Indonesia is the number of world tourists that improve per year. The data as reported by nippon.com as follows:

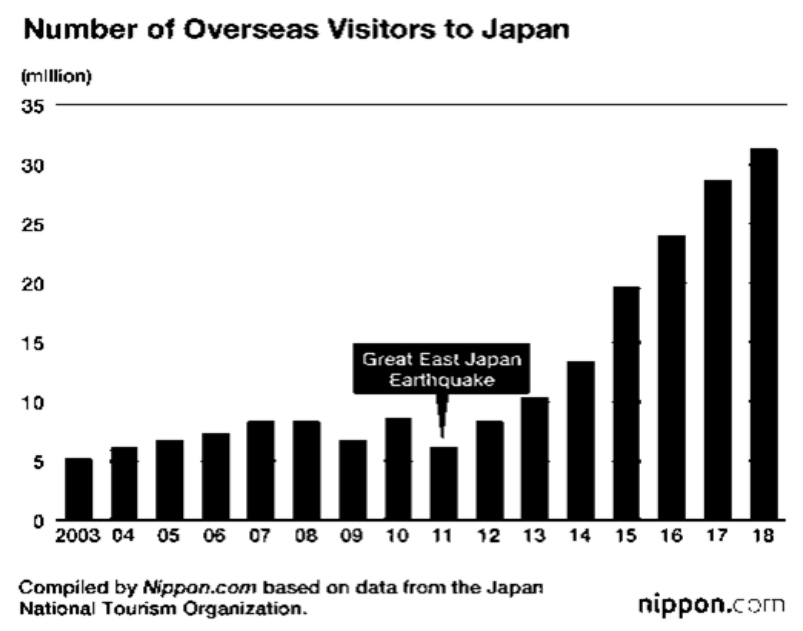

Fig. 7. Number of overseas visitors to Japan.

Based on the data, the number of overseas visitors to Japan has improved every year except in 2011 due to the huge natural disaster that destroys Japan. The number of Indonesian tourists to Japan is also improving per year. Most Indonesian people after knowing Japanese culture will be interested in visiting the country directly. The data on the improvement of Indonesian tourism is presented by one of the Japanese travel agents Indonesia branch of ' HIS Travel Indonesia' as follows:

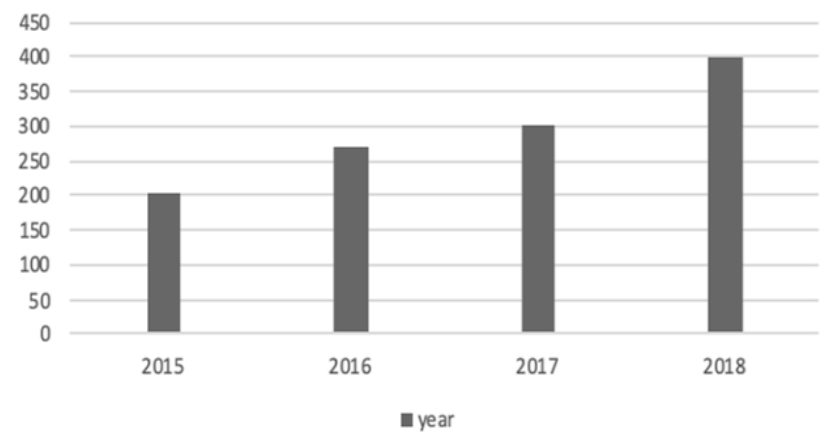

Fig. 8. Number of Indonesian tourists visited Japan (source: HIS). 
Based on both data, it can be concluded that the Indonesian community's mandate to earn a living and work in Japan is very high. Nowadays many collaborations have been made between Japan and Indonesia, especially in the cooperation of Indonesian workers in Japan.

\section{Conclusion}

The challenges and problems faced by each country will keep changing, especially after the globalization era. Japan is one of the countries that has reached economic maturity but must face a demographic crisis that impacts the crisis of employees caused by several factors including the reluctance of Japanese women to get married. Both of Japanese government and the private sector have tried various ways to solve the problem of the number of workers by using artificial intelligence to replace the role of humans in several job positions and extend the retirement age for elder people. Although the use of artificial intelligence is used it cannot replace all human work positions, and also the retirement age for elderly workers can only extend the working period for several years.

To solve one of the problems and challenges for the country, Japan is undertaking cultural diplomacy efforts aimed specifically at countries in the Asian region. By creating a special institution named the Japan Foundation to promote traditional and modern culture. The traditional cultures that are often promoted ikebana and chanoyu, while modern culture is anime. Even the Japanese government openly states using anime as their tool for the implementation of their cultural diplomacy.

The various programs created by the Japanese government and the Japan Foundation that make the people from other countries, including Indonesian people, are very interested in Japan. Therefore, it raises the interest of foreign people to settle and work in Japan, due to the wage standard is higher and its culture is considered attractive. It does not solve the problem of employee number crisis in Japan directly despite there will be a risk of Japanese people who do not like to live side by side with foreign immigrants. Another impact of Japanese cultural diplomacy, such as the improvement of foreign tourists to Japan per year which impact state income through the tourism sector.

\section{References}

[1] J. Melissen, The new public diplomacy. Springer, 2005.

[2] H. B. Feigenbaum, Globalization and cultural diplomacy. Center for Arts and Culture, 2001.

[3] The Japan Foundation, "Japanese Film Screenings Overseas," The Japan Foundation, 1998. [Online]. Available: https://www.jpf.go.jp/e/project/culture/media/oversea/index.html.

[4] J. C. Abegglen, "Japan's Industries and Companies: Economic Dynamism and Social Continuity," Econ. Reform Japan Can Japanese Chang., 2001.

[5] K. Kelsky, Women on the Verge. Duke University Press, 2001.

[6] D. S. Massey, J. Arango, G. Hugo, A. Kouaouci, A. Pellegrino, and J. E. Taylor, "Theories of international migration: A review and appraisal," Popul. Dev. Rev., pp. 431-466, 1993. 